\title{
Accuracy of Automatic Number Plate Recognition (ANPR) and Real World UK Number Plate Problems
}

\author{
Mike Rhead, Robert Gurney, Soodamani Ramalingam \\ School of Engineering and Technology \\ University of Hertfordshire \\ College Lane Campus \\ Hatfield, Herts AL10 9AB, UK \\ Email: s.ramalingam@herts.ac.uk
}

\author{
Neil Cohen \\ Home Office \\ Centre for Applied Science and Technology \\ Sandridge \\ St. Albans, Herts AL4 9HQ, UK
}

\begin{abstract}
This paper considers real world UK number plates and relates these to ANPR. It considers aspects of the relevant legislation and standards when applying them to real world number plates. The varied manufacturing techniques and varied specifications of component parts are also noted. The varied fixing methodologies and fixing locations are discussed as well as the impact on image capture.
\end{abstract}

Key words-ANPR, number plates, optical character recognition, National ACPO ANPR Standards (NAAS), ANPR British Standards, Registration Marks Legislation, misreads, missed reads.

\section{INTRODUCTION}

Automatic Number Plate Recognition (ANPR) within the UK is a powerful tool and its policing purpose is to deny criminals the use of our roads [1]. It is a major tool that is used to improve the security and safety of the general public. In standard use, ANPR is remarkably accurate. However, the purpose of this work is to look at the occasions when ANPR fails to capture the vehicle registration mark (VRM) correctly. By reviewing the mode of failure it is hoped to be able to improve the performance of ANPR. Some main causes of ANPR failures area as follows:

Fixing Screws: Depending upon the character of the VRM and the juxtaposition of a fixing screw misreads can occur. Such misreads can be consistent or inconsistent and the paper gives examples of this. An experiment whereby small diameter anti-tamper screws were used to secure the number plate to the vehicle is discussed as well as the relative improvement in correct read rate.

Fixing Adhesives: Depending upon the method of manufacture of the number plate, fixing adhesives can also affect the retro-reflective layer and the photographic properties of the number plate. This is caused by absorption of the adhesive into the retro-reflective layer and subsequent impact on its reflective properties.

Visible and near-infrared Spectrum: ANPR systems can use both the visible and near infra-red spectrum. The appearance of real world number plates can be significantly different when comparing monochromatic or black and white images from the visible spectrum and the near infra-red spectrum.
The main cause of a misread read has been found to relate to screws and screw caps where the fixing is within the lettering of the VRM. The main failure mode for ANPR cameras has been found to relate to fixings. The implications for license plate manufacture [2], fixing methodology, legislation and standards are discussed in the following sections.

\section{LITERATURE REVIEW}

The authors of the paper work with Police ANPR systems. Their work on other aspects of ANPR is well progressed and further publications are planned. Countermeasures, cloned plates and vehicles moving without number plates are an inevitable aspect of this work and progress has already been made in this area. However, the outcome of this aspect of work will not be published nor put into the public domain.

This is a pioneering work; a literature review [3-6] conducted by the authors revealed that there is no other published real-world research. These papers assume ideal experimental conditions. The papers that were identified assumed ideal conditions.

Our initial work began in 2006 through field trials determining the accuracy of hot lists. As a result of this work changes were made to a number of hot lists to improve their accuracy. In 2009, our attention turned to the cause of misreads (not read correctly by ANPR systems) and by 2010 we were looking at the cause of missed reads (data missed completely). During 2009 we also began researching the NAAS Standard in depth. In 2010 we reviewed the British Standard test for number plates, the details of the NAAS standard and also the differences in performance of the different ANPR cameras available and captured a lot of data relating to these aspects. We are continuing to experiment with camera settings (including software) and capture rate.

Field tests have been carried out for a range of ANPR cameras under identical conditions to assess performance of the camera, adjustment of camera setting and the performance of the software within the camera [7]. Here, we are considering fixings within a VRM. The results of this wide ranging work are expected to help improve the accuracy of ANPR to an even higher level. 


\section{FIXINGS}

The following two images in Fig. 1 are of the same number plate. Fig. 1(a) was captured in the visible spectrum and Fig. 1(b) captured in the near infrared spectrum. The impact of the screw cap can be seen between the two images. The screw cap is much easier to see in the near infrared image.

Other unpublished work indicated that screws and screw caps close to or within the lettering of the vehicle registration mark could cause difficulty for optical character recognition which in turn can lead to misreads or missed captures. The impact of the screw fixing can be much greater under near infrared imagery. This aspect is discussed in detail in the paper. Figure 1 gives an example of the difference.

\section{A. Initial Tests}

Some of our initial (unpublished) work into misreads indicated that ANPR misreads were caused by a number of factors that could be exhibited by "real world" number plates. The misreads were assessed and broken down into 5 categories [Table I]. Our initial work looked at capture rates and misread rates for vehicles giving a match to hot lists such as no insurance. As an extension of this work the causes of 700 misreads to be studied in depth.

This initial work on 700 misreads suggested that number plate fixings (screws and screw caps) accounted for $72.6 \%$ of misreads. Results of analysis indicate that the top 10 characters that accounted for $55.6 \%$ of incorrect reads and these are related to screws or screw caps [Table II]. These results are typical of the issue.

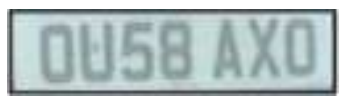

(A) VISIBLE SPECTRUM IMAGE

FIGURE 1: DIFFERENCE BETWEEN VISIBLE SPECTRUM AND INFRARED IMAGE CAPTURES

TABLE I: ATtRIBUTABLE CAUSE OF MisREAD

\begin{tabular}{|l|c|c|}
\hline & $\begin{array}{l}\text { Percentage } \\
\text { Misreads }\end{array}$ & $\begin{array}{l}\text { Cumulative } \\
\text { percent }\end{array}$ \\
\hline Screw cap & 72.6 & 72.6 \\
\hline Marks & 23.0 & 95.6 \\
\hline Obscured & 1.8 & 97.4 \\
\hline Broken & 1.8 & 99.2 \\
\hline Illegal font & 0.9 & 100.0 \\
\hline
\end{tabular}

TABLE II: ATtRIBUTABLE CAUSE OF MisREAD

\begin{tabular}{|c|c|}
\hline Character & Cumulate \% \\
\hline $\mathrm{G}$ & 7.7 \\
\hline $\mathrm{S}$ & 14.8 \\
\hline $\mathrm{O}$ & 21.9 \\
\hline $\mathrm{C}$ & 27.8 \\
\hline 4 & 33.1 \\
\hline $\mathrm{D}$ & 37.9 \\
\hline $\mathrm{K}$ & 42.6 \\
\hline $\mathrm{K}$ & 47.3 \\
\hline 7 & 51.5 \\
\hline $\mathrm{M}$ & 55.6 \\
\hline
\end{tabular}

The fixing problem is more prominent at certain positions on the Number Plate (NP). Fig. 2 indicates the position or location of the misread character from this work. The post 2001 UK Number Plate regulation introduced a space between the 4th and 5th characters. For the same 700 NPs, the character at position 2 is the most commonly misread location (34\%) and position 5 is the second highest misread location (16\%). These two positions account for $50 \%$ of misreads caused by screws and screw caps.

\section{B. Further Field Tests}

A number of vehicles in the UK have number plates that begin with the letters OU [Figure 1]. Ten specific vehicles were selected from a Police fleet each one having a screw/screw cap fitted within the centre of the character U. Each had their movements monitored over a two month period. There were 997 captures of which $713(71.5 \%)$ were correctly read indicating a misread rate of $28.5 \%$ for these plates. Of the 284 misreads the $\mathrm{U}$ was interpreted incorrectly as other characters [Table III].

Five of the sample vehicles then had their fixing screw replaced with smaller diameter anti-tamper screws in order to try to reduce the footprint of the fixing. There were 359 captures for the 5 vehicles. Of these, 358 (99.7\%) were correctly read indicating a misread rate of $0.3 \%$. The difference in screw sizes are indicated in Figure 3.

From this test we infer that a simple change to the diameter of the screw head used can significantly impact the accuracy of the ANPR systems. The diameter of the standard fixing was about $12 \mathrm{~mm}$ and that of the anti-tamper fixing was $6 \mathrm{~mm}$. The footprint area of the fixings went from $113 \mathrm{~mm}^{2}$ to $28 \mathrm{~mm}^{2}$. In this test, our result indicated a $98.9 \%$ improvement in accuracy! 
FIGURE 2: POSITION OF MISREAD LETTER

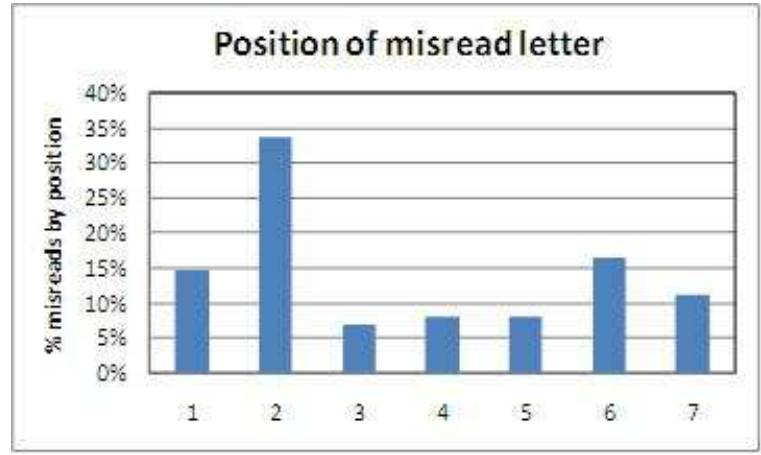

TABLE III: STATISTICS OF INCORRECT READS

\begin{tabular}{|ccc|}
\hline $\begin{array}{c}\text { Interpreted } \\
\text { character }\end{array}$ & Frequency & $\begin{array}{c}\text { Cumulative } \\
\text { frequency }\end{array}$ \\
\hline $\mathrm{W}$ & $25 \%$ & $25 \%$ \\
\hline $\mathrm{O}$ & $25 \%$ & $50 \%$ \\
\hline $\mathrm{N}$ & $25 \%$ & $75 \%$ \\
\hline $\mathrm{H}$ & $10 \%$ & $85 \%$ \\
\hline $\mathrm{M}$ & $10 \%$ & $95 \%$ \\
\hline 8 & $5 \%$ & $100 \%$ \\
\hline
\end{tabular}

\begin{tabular}{|l|l|}
\hline $\begin{array}{l}\text { Infrared plate patch } \\
\text { Small diameter anti-tamper } \\
\text { screw }\end{array}$ & $\begin{array}{l}\text { infrared piate patch } \\
\text { Standard scres cap }\end{array}$ \\
\hline
\end{tabular}

FIGURE 3: DIFFERENCE SCREW SIZES UNDER INFRA-RED

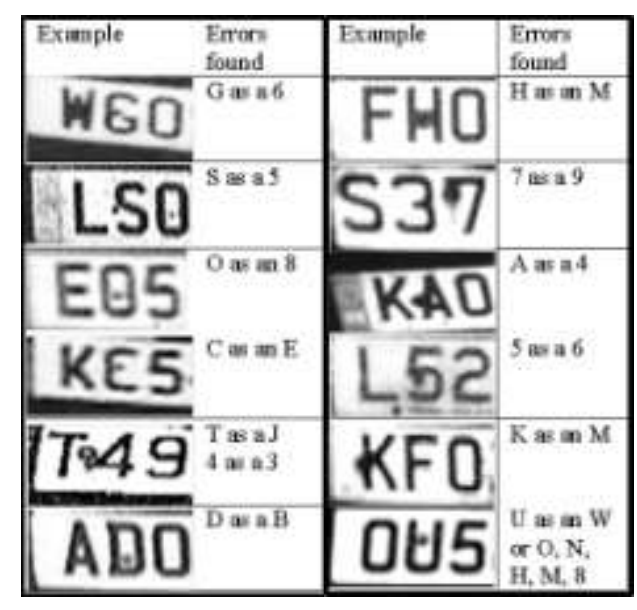

FIGURE 4: SCREW POSITIONS AFFECTING ANPR INTERPRETATIONS
TABLE IV: RESULTS OF THE 1,238 VEHICLE SAMPLE

\begin{tabular}{|l|c|c|}
\hline Screw fixings & $\begin{array}{l}\text { Number in } \\
\text { category }\end{array}$ & $\%$ \\
\hline Visible screws & 966 & 78 \\
\hline $\begin{array}{l}\text { Visible screws within the characters of } \\
\text { VRM }\end{array}$ & 774 & 63 \\
\hline Outside the characters of VRM & 192 & 15 \\
\hline No visible fixings & 272 & 22 \\
\hline
\end{tabular}

\begin{tabular}{|c|c|c|}
\hline $\begin{array}{l}\text { Number plate } \\
\text { imeje }\end{array}$ & Msrepresentation & Cassa \\
\hline LSNOW & $\begin{array}{l}\text { LENOWW tepresentedas } \\
\text { LSNOW }\end{array}$ & yedow screw cap \\
\hline $\mathrm{FI} / 0 \mathrm{HN}$ & $\begin{array}{l}\text { F11 OHN zepresented as } \\
\text { F1 } 30 \mathrm{HN}\end{array}$ & Dlack screnr cap \\
\hline CHILL 0 & $\begin{array}{l}\text { C111 LLO represented as } \\
\text { CHLL O }\end{array}$ & bieck screw cep \\
\hline IN & $\begin{array}{l}\text { L11 AHN represented as } \\
\text { LHAHN }\end{array}$ & black screw cap \\
\hline NIII A.6.5 & $\begin{array}{l}\text { N111 AGC represented } 86 \\
\text { N1 } 11 A G C \text {. }\end{array}$ & black scren cap \\
\hline P EOOPER & $\begin{array}{l}\text { PEOD PFR represented as } \\
\text { P COOPER }\end{array}$ & yolowr and black sarew ceps \\
\hline PGODPER & $\begin{array}{l}\text { P600 PER represented as } \\
\text { PCOCPER }\end{array}$ & $\begin{array}{l}\text { White screw in the } 6 \text { but } \\
\text { appears bleck under infrased }\end{array}$ \\
\hline
\end{tabular}

Table V Examples of misrepresented number plates

Further research identified screw positioning as being a key factor causing mis-reads and resulting in incorrect interpretations by ANPR systems as illustrated in Figure [3].

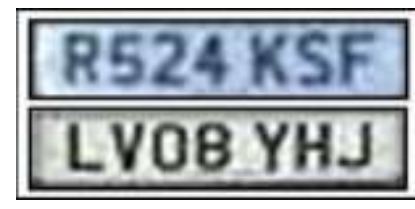

A) VisiBLE SPECTRUM

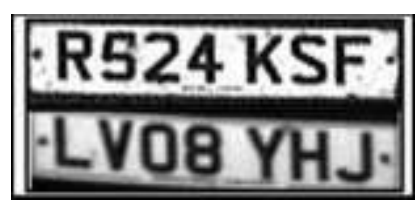

B) NEAR INFRARED SPECTRUM
FIGURE 5. DIFFERENCE IN VISIBLE SPECTRUM VS IR IMAGE CAPTURE

\section{Confidence Measures}

Having determined that there is a significant problem that arises from screw fixings, further trials were undertaken to try to determine the extent of the problem within the UK. To this end, the fixing methodology was analysed for a sample of 1,238 vehicles, the results of which are as shown in Table IV.

\section{Fixing Screws and Resulting Images in Visible and Near- Infrared Spectra}

The legislation requires that where the fixing screw goes through a white background layer a white screw/screw cap is used. Similarly a yellow fixing is used for the rear and a black fixing goes through the actual lettering. The purpose of this is to ensure that the number plate is easily read by the human eye for identification and prosecution purposes.

The infrared spectrum used in ANPR applications to capture number plates is just outside human vision $[8,9]$. To 
give an indication of the difference two sets of number plates captured in the visible spectrum are shown in [Fig. 5A] and the same plates captured in the near infra-red spectrum are shown in [Fig. 5B]. The fixing screws at the left and right hand edge of the number plates appear as black dots in Figure 5B which can contribute to mis-reads.

The reason for this is that the white plastic caps used as part of the fixing are infrared absorbers and have no retro-reflective properties. It would be illegal to use retro-reflective fixings on a number plate. The difficulty faced as a result of this is that the fixings within the VRM lettering appear as large black full spots within the lettering and this can confuse the OCR software depending upon the relative size and position of the fixing with respect the character within the VRM.

\section{E. Screw Caps and Spacing}

Illegal use of screw caps and spacing in the visible spectrum contravenes the statutory instrument. Table VI gives a few examples of the illegal use of screws (as well as illegal spacing). Such plates are illegal because they "deceive" the eye as well as breaching number plate spacing regulations. Such number plates do cause ANPR misreads.

Further work is also planned where we will look at the impact of variable spacing using the standard UK number plate Charles Wright font.

\section{F. Fixings under Infrared}

For the data considered in Section III B (Further Field Tests) the reported misread rate of $28.5 \%$ was due to a screw in the letter $U$ and the size of the screw fixing [Fig. 7]. A further analysis of 1,287 random number plates indicated that a large number of plates have screws within the characters of the VRM, typically $63 \% \pm 4 \%$. This does not imply that $63 \%$ of number plates can be misread because of screw fixings; the proportion of number plates giving misreads will be well below this. Thus, one can easily conclude that the elimination of screw fixings from number plates will improve the accuracy of ANPR.

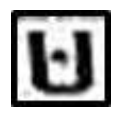

FIGURE 7: APPEARANCE OF A WHITE SCREW CAP FIXING ON A WHITE RETRO-REFLECTIVE NUMBER PLATE UNDER NEAR INFRARED

\section{G. ANPR Infrared Images}

The majority of number plate images used for optical character recognition (OCR) are monochromatic images. The images are normally captured by standard optical cameras fitted with a visible spectrum and/or near infrared filters.

The infrared image is based upon the contrast between the retro-reflective layer and characters of the VRM. Screws and screw caps attenuate infrared and appear as black marks shown in Figure 4 and this in turn can confuse OCR.

In summary, having considered the issue of one can see that screw caps fitted within the type face can have a detrimental effect on the ability of the human eye to recognise the VRM correctly. At the same time, the situation can be even worse under infrared. The legislation in this area requires clarification as there are a number of ambiguous interpretations.

\section{INTERPRETATION OF THE STATUTORY INSTRUMENT AND BRITISH STANDARD}

\section{A. Visible versus the near infrared spectrum}

Greater clarity is required in the definition of the Act and the Standard. The Act appears to cover infrared images because it refers to "camera and film or any other device" and "true photographic image". There is no definition or case law with respect to this and opinion is divided. The British Standard can also be seen as ambiguous:

According to the British Standard, the luminous intensity in a given direction of a source that emits monochromatic radiation of frequency $555 \mathrm{~nm}$ is defined by candela abbreviated as $c d$.

The units of retro-reflectivity measurement of radiance is given by

where

$$
\rho=\mathrm{cd} / \mathrm{lx} / \mathrm{m}^{2}
$$

$$
\begin{aligned}
& \mathrm{cd} \rightarrow \text { candela, luminous intensity } \\
& \mathrm{lx} \rightarrow \text { lux, luminous flux per unit area } \\
& \mathrm{sr} \rightarrow \text { steradian, a unit of solid angle } \\
& \mathrm{m}^{2} \rightarrow \text { area in square meters }
\end{aligned}
$$

lux is defined by:

$$
1 \mathrm{x}=1 \mathrm{~cd} . \mathrm{str} / \mathrm{m}^{2}
$$

Substituting (2) in (1), the retro-reflectivity unit of measure becomes:

$$
\rho=\mathrm{cd} / \mathrm{cd} \cdot \mathrm{sr} / \mathrm{m}^{2} / \mathrm{m}^{2}
$$

The equation cancels and becomes

$$
\begin{aligned}
\rho & =1 / \mathrm{sr} \\
& =\text { per steradian } \\
& =\text { per unit of solid angle }
\end{aligned}
$$

Thus, $\rho$ is, in fact, a dimensionless unit and cancels to become a per steradian.

The measurement relates to reflectance and is independent of the wavelength of the radiation used for the test. That is, the ratio of the total amount of radiation reflected by a surface to the total amount of radiation incident on the surface. 
The use of candela is taken by some to infer that the visible spectrum is the required wavelength range because the unit candela is mentioned. However, the British Standard [10] refers to CIE 15 [11] and CIE 54 [12]. To measure the retroreflectivity of the characters and backing layer of a UK number plate the standard requires illuminant A. I Illuminant A is based on a tungsten filament bulb operating at a defined temperature of $2,856{ }^{\circ} \mathrm{K}$. Iluminant $\mathrm{A}$ has a defined wavelength range $(300 \mathrm{~nm}$ to $830 \mathrm{~nm})$ and spectral power. The wavelength range covered enters the near infrared spectrum. It is not clear if the British Standard is required to be carried out at $555 \mathrm{~nm}$ or over the spectrum and spectral power defined in CIE 15 (300 to $830 \mathrm{~nm})$.

The key issue here relates to definition and interpretation of Statutory Instrument No.561 [13]. The screw fixings clearly interfere with the optical character recognition software. The key question relating to these fixings is - are they legal?

The requirements of the CIE standards were originally applied to UK roads signs and markings with respect to driver safety. They were subsequently incorporated into BS AU 145d for UK number plates.

Some infrared ANPR systems operate at up to $940 \mathrm{~nm}$. As a consequence the authors would like to see the defined range of $300-830 \mathrm{~nm}$ amended within the British Standard. A range of $300-1,000 \mathrm{~nm}$ would be preferred with reflectance measured as an integral and at $5 \mathrm{~nm}$ intervals. This would indicate if the number plate had uniform reflectance properties over the defined wavelength range.

\section{B. Performance standards for fixings}

The National Association of Chief Police Officers Automatic Number Plate Recognition Standards (NAAS) [14] notes minimum performance standards.

As has been demonstrated fixings can cause an ANPR misread. If fixings do cause a misread they can be regarded as an illegitimate UK plate. Under such circumstances these plates can be discounted from the compliance test. This is not unreasonable if the optimum performance possible (ideal world) of the system is being considered. We would like to see an additional measure whereby misreads attributable to fixings are also declared. We propose that changes to UK number plate legislation would tackle the main cause of ANPR misreads.

\section{Variety in UK and Schengen number plates}

Beyond the consideration of screw fixings there is a wide variability in font, spacing and other marks in the registration area of number plates within the UK. UK includes Northern Ireland, Isle of Man and Channel Islands.

Under EU rules countries are, in effect, borderless for member states. This is discussed more fully in another paper by the authors [5]. There is an increased variety of number plates being presented to ANPR systems and ANPR systems should develop further to take this into account.

\section{1) UK VARIETY}

National ACPO ANPR Standard (NAAS) [6] notes that for the avoidance of doubt, number plates from Northern Ireland, Isle of Man and Channel Islands are regarded as UK number plates.

The proportion of Northern Ireland, Isle of Man and Channel Island number plates is comparatively small when compared to standard UK plates. It is interesting to explore the performance requirement for these plates under the NAAS standard and the possible implications for ANPR manufacturers and suppliers.

The Crown Dependencies of the Channel Islands and the Isle of Man are outside the United Kingdom and European Union, and have registration marks that differ from those used in the UK.

Examples of the type and style of number plates included are given in Fig. 6.
BDZ 7459

A) NORTHERN IRELAND

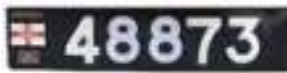

C) GUERNSEY

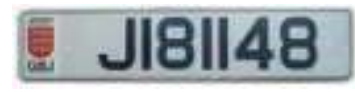

B) JERSEY

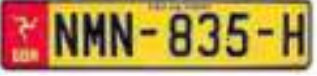

D) ISLE OF MAN
FIGURE 6: VARIETY IN NUMBER PLATES

2) ANPR algorithms to handle Schengen Community number plates.

The series of images [App. A-B] relate to a sample of Schengen community number plates and are given to illustrate the challenge given to OCR readers in ANPR systems. The difference in font, syntax, symbols and spacing pose a problem to OCR utilised in the UK.

\section{FUTURE WORK}

ANPR captures are extremely accurate. This work has determined that some number plates can be problematic for ANPR cameras and that the main reason for a misread for a UK number plate is caused by screw fixings. Screw fixings within a VRM can confuse an ANPR system and the result could be a complete failure to capture or a misread. 
Future work we will consider includes:

- Character spacing

- Camera set up

- Infrared illumination

- Instantaneous traffic flow rates compared to manufacturers hourly plate rate capacity

- Comparative testing of different systems using a defined data set

- Various counter measure testing

- Number plate manufacturing techniques

\section{ACKNOWLEDGEMENTS}

Dr. Vivienne Lyons - Home Office; Detective Superintendent Paul Ealham - Hertfordshire Constabulary; Lisa Gilmore - Department for Transport; Alastair Thomas - Home Office; Mark Jones - National Policing Improvement Agency; Frank Whiteley - former Chief Constable Hertfordshire.

\section{References}

[1] ACPO ANPR Steering Group (2005). Denying Criminals the Use of the Roads. Report by the British Association of Chief Police Officer's ANPR Steering Group, March 2005.

[2] R. Gurney, M. Rhead, Private Discussions with British Number Plate Manufaturer's Association (BNMA), 2011.

[3] Z. Musoromy, S. Ramalingam. N. Beekoy, Edge Detection comparison for License Plate Detection, Proc., 11th International Conference on Control, Automation, Robotics and Vision(ICARV2010), IEEE sponsored and organized by NTU, Singapore, 7-10 Dec. 2010, pp.1133-1138.

[4] Z. Jeffrey, S. Ramalingam, High Definition License Plate Detection Algorithm, Proc., IEEE SoutheastCon "Innovating for a Better Tomorrow", Mar.15-18, 2012, Orlando, Florida, US.

[5] Barry Watson and Karen Walsh, The Road Safety Implications of Automatic Number Plate Recognition, Report, The Centre for Accident Research \& Road Safety, Queensland, Feb. 2008.

[6] Tran Duc Duan, Tran Le Hong Du, Tran Vinh Phuoc, Nguyen Viet Hoang, Building an Automatic Vehicle License Plate Recognition System, International conference in Computer Science, Can Tho, Vietnam, Feb.21-24, 2005.

[7] Robert Gurney, Mike Rhead, Soodamani Ramalingam, Neil Cohen, Working Towards an International ANPR Standard - An Initial Standard into the UK Standard, The 46th Annual IEEE International Carnahan Conference on. Security Technology. 1518 October 2012, Boston, Massachusetts, USA, accepted.

[8] Some paradoxes, errors, and resolutions concerning the spectral optimization of human vision BH Soffer \& DK Lynch http://www.phys.ufl.edu/ hagen/phz4710/readings/AJPSofferLy nch.pdf, accessed 26 Mar 2012.

[9] H. Roy, "Wavelength considerations", Instituts für Umformund Hochleistungs,

http://web.archive.org/web/20071028072110/http://info.tuwien.a c.at/iflt/safety/section1/1_1_1.htm, accessed 26 Mar.2012.

[10] BS AU 145d:1998, British Standards Institution, 15 January 1998, ISBN 0-580-28985-0,

[11] The International Commission of Illumination (CIE) Publication No. 15 (CIE), 1986 Colorimetry
[12] The International Commission of Illumination (CIE) Publication No. 54 (CIE) Retro-reflection definition and measurement

[13] "Statutory Instrument No. 561 The Road Vehicles (Display of Registration Marks) Regulations," 2001,

[14] The National ACPO ANPR Standards (NAAS) National Policing Improvement Agency June 2012

\section{APPENDIX A: LIST OF SCHENGEN STATES}

\begin{tabular}{|l|l|l|} 
Austria & Germany & Netherlands \\
Belgium & Greece & Norway \\
Bulgaria & Hungary & Poland \\
Cyprus & Iceland & Portugal \\
Czech Republic & Italy & Romania \\
Denmark & Latvia & Slovak Republic \\
Estonia & Lithuania & Slovenia \\
Finland & Luxembourg & Spain \\
France & Malta & Sweden \\
\hline
\end{tabular}

\section{APPENDIX B: SOME EXAMPLES OF SCHENGEN COMMUNITY NUMBER PLATES}

\begin{tabular}{|c|c|c|}
\hline & AA-229-AАЕ & $1233 \mathrm{CD} 3$ \\
\hline allint & GGI $8165 \mathrm{BL}$ & 7137 \\
\hline tugal & $45 \cdot 72 \cdot X Q$ & \\
\hline atia & BZD-608.EC & \\
\hline ngary & KKD:006 & \\
\hline ech Republic & $4 A 2: 3000$ & $2 \mathrm{H} 2: 714$ \\
\hline Igium & |KAZ:813]" & $1: \mathrm{ABC} \cdot 0$ \\
\hline ithuania & $A O G: 830$ & \\
\hline Poland & ERA 81TL & $\sqrt{n-2}$ \\
\hline Romania & B $78 \mathrm{BGG}$ & B 58 \\
\hline Bugaria & CA7845XC & $T \times 2503$ \\
\hline tvia & FM-5463 & \\
\hline many & SB:A5526 & 6 KA: \\
\hline & $K=510 \mathrm{BV}$ & W*26285T \\
\hline & $123 \mathrm{ABC}$ & $\bar{c}$ \\
\hline
\end{tabular}

